\title{
Balanço de DQO particulada em um reator de eletrocoagulação/ flotação tratando efuente de curtume
}

\section{Particulate COD balance of particulate cod in eletrocuagulation/ flotation reactor treating tannery effluent}

\author{
Rodrigo Babora Borri ${ }^{1}$; Renata Medici Frayne Cuba ${ }^{2}$; Francisco Javier Cuba Teran ${ }^{3}$
}

Resumo

O balanço de massa de material orgânico particulado foi estudado na forma de DQO, por meio da operação de um reator de eletrocoagulação/flotação (ECF) que tratava o efluente de uma indústria de curtimento de couro. $\mathrm{O}$ reator foi operado em bateladas sequenciais durante $65 \mathrm{~min}$ depois dos quais alcançou $55 \%$ de remoção de DQO. Embora os sólidos voláteis também fossem removidos (40 \% de remoção), a concentração de sólidos fixos, e consequentemente, a de sólidos totais, apresentou-se maior no efluente do reator com relação à entrada. Esse fenômeno foi atribuído à massa de $\mathrm{NaCl}$ adicionada visando aumentar a condutividade do despejo.

Palavras-Chave: Eletrocoagulação. Flotação. Remoção de DQO particulada.

\begin{abstract}
Mass balance or particulate organic matter was studied in terms of COD, by means of electrocoagulation/ flotation (ECF) reactor treating tannery effluent. Reactor was operated in fill and draw (batch) mode. Operating in hydraulic residence time of 65 minutes, ECF reactor reached $55 \%$ COD removal. Although volatile solids were also removed from liquid phase (removal of $40 \%$ ), fixed solids concentration, and hence total solids concentration, showed to be higher in withdrawn effluent than in ECF's influent. This was assigned to $\mathrm{NaCl}$ added in order to enhance conductivity in wastewater.
\end{abstract}

Keywords: Electrocoagulation. Flotation. Particulate COD removal.

\section{Introdução}

A remoção de material orgânico particulado detectado por meio de DQO, geralmente é desenvolvida por meio de unidades de decantação, cuja eficiência depende das características de sedimentabilidade dos sólidos, o que de fato se traduz em áreas menores das unidades de sedimentação. Alguns pesquisadores dirigiram seus esforços ao desenvolvimento de unidades que visavam otimizar esse processo de tratamento (FENG et al., 2007;

\footnotetext{
${ }^{1}$ Aluno do curso de Engenharia Ambiental da Universidade Estadual Paulista.

2 Química e doutora em Hidráulica e saneamento pela EESC/USP, professora da Universidade do Oeste Paulista.

3 Engenheiro civil e doutor em Hidráulica e Saneamento pela EESC/USP, professor da Universidade Federal de Goiás. email: pacoufg@gmail.com
} 
LEFEBVRE; VASUDEVAN; TORRIJOS，2005; MURUGANANTHAN; RAJU; PRABHAKAR, 2004), embora poucos testaram o emprego da ECF.

A eletrocoagulação é um processo que complementa a eletrólise da água com a coagulação química. Quando esses fenômenos são aliados à flotação, pequenas bolhas de gás capturam os flocos formados em seu caminho ascendente e os separam da fase líquida. Inclusive, algumas substâncias dissolvidas são também removidas por meio de adsorção (EMAMJOMEH; SIVAKUMAR, 2009).

Este trabalho relata as experiências de um estudo desenvolvido visando verificar a eficiência da eletrocoagulação/flotação aplicada na remoção de matéria orgânica particulada presente no efluente industrial de um processo de acabamento de couro.

\section{Materiais e metodos}

A matéria orgânica particulada presente no despejo líquido estudado neste trabalho estava presente em um processo de acabamento de couro, o mesmo que recebia como matéria prima o wet blue, e o submetia a rebaixamento, re-curtimento e tingimento. Essas operações geravam um efluente com elevadas concentrações de sólidos suspensos, tornando-o em um líquido potencialmente ofensivo ao meio ambiente e com qualidade incompatível com a legislação ambiental.

O liquido afluente ao sistema foi retirado diariamente a partir da entrada da estação de tratamento de efluentes industriais, ao longo do período de operação do experimento. Enquanto o sistema não estava sendo alimentado, o líquido permanecia sob refrigeração a $4 \mathrm{oC}$. Antes de cada batelada o sistema foi alimentado com $4 \mathrm{~L}$ de efluente bruto previamente homogeneizado.

O sistema piloto estava constituído por um reator em acrílico, com $10 \mathrm{~L}$ de volume (4 L de volume útil), em cujo interior foram dispostos seis eletrodos de alumínio $(15 \mathrm{~cm} \times 15 \mathrm{~cm} \times 0,5 \mathrm{~cm})$. Esses eletrodos estavam montados com espaçamento de $5 \mathrm{~cm}$ sobre um cilindro de resina, sendo que os dois eletrodos colocados nas extremidades foram conectados a uma fonte de corrente contínua de 10 V. Na Figura 1 é mostrada a fotografia do sistema.

Figura 1 - Fotografia do sistema

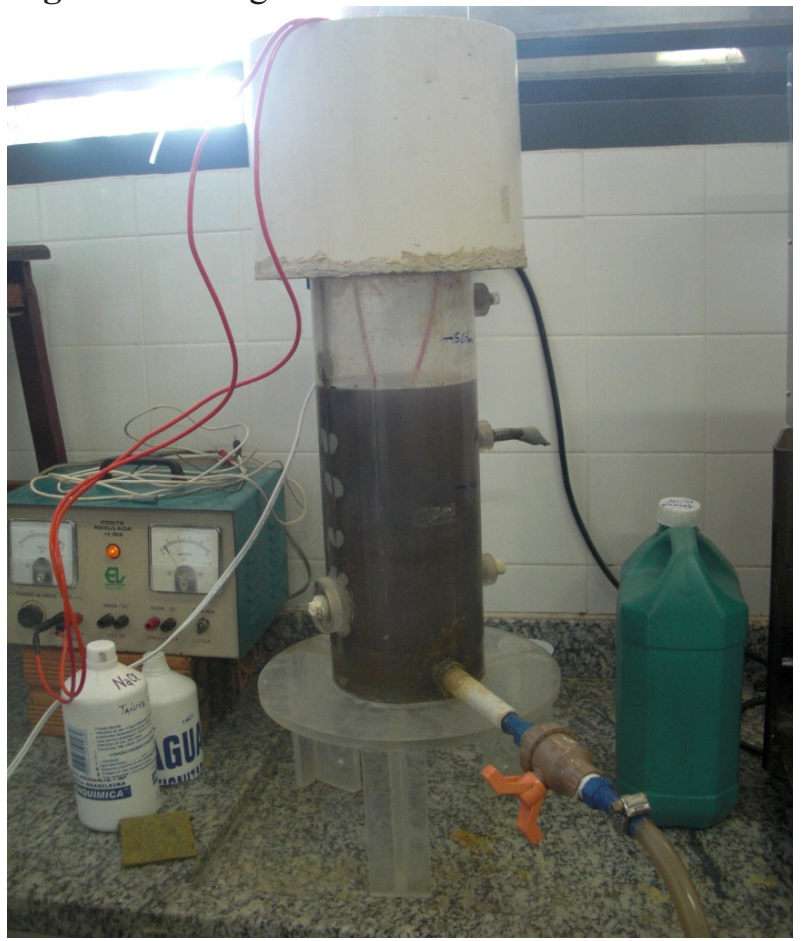

Fonte: Elaborada pelos autores

Em cada ciclo de funcionamento o despejo líquido tinha sua condutividade corrigida para 4 $\mathrm{mS} . \mathrm{cm}^{-1}$ por meio da adição de $7 \mathrm{~g}$ de $\mathrm{NaCl}$, essa operação permitia atingir densidades de corrente da ordem de $22 \mathrm{~A} . \mathrm{cm}^{-2}$. Posteriormente, a corrente era desligada por 20 min para promover a flotação na qual as bolhas viajavam em sentido ascendente até alcançar a superfície. Depois do final de cada ciclo o efluente era retirado da unidade.

Os métodos publicados em Standard Methods for the Examination Water and Wastewater (APHA, AWWA, WEF, 1998) foram aplicados para todas 
as análises efetuadas, a DQO foi desenvolvida seguindo o método $5220 \mathrm{D}$, a turbidez seguindo o método $2130 \mathrm{~B}$, a condutividade seguindo o método 2510 A, os sólidos totais seguindo o método 2540
B e os sólidos voláteis seguindo o método 2540 E.

As características típicas do efluente bruto são apresentadas na Tabela 1.

Tabela 1 - Características típicas do efluente bruto

\begin{tabular}{lccc}
\hline Parâmetro & Valor médio & Parâmetro & Valor médio \\
\hline DQO (mg. $\left.\mathrm{L}^{-1}\right)$ & 3500 & Condutividade $\left(\mathrm{mS} . \mathrm{cm}^{-1}\right)$ & 3 \\
Turbidez (NTU) & $*$ & Sólidos totais $\left(\mathrm{g} . \mathrm{L}^{-1}\right)$ & 5,5 \\
pH & 9,6 & $*$ valor além do limite de detecção & \\
\hline
\end{tabular}

Fonte: Elaborada pelos autores

O sistema foi operado em três Fases de acordo com a Tabela 2.

Tabela 2 - Descrição do funcionamento do sistema

\begin{tabular}{ll}
\hline FASE & \multicolumn{1}{c}{ FUNCIONAMENTO } \\
\hline Inicial & $\begin{array}{l}\text { Fase de testes em que foram } \\
\text { definidos } \\
\text { eletrólise e de flotação }\end{array}$ \\
Primeira & $\begin{array}{l}\text { No afluente bruto, os parâmetros } \\
\text { monitorados foram medidos } \\
\text { somente por ocasião da coleta }\end{array}$ \\
& $\begin{array}{l}\text { No afluente bruto, os parâmetros } \\
\text { monitorados foram medidos antes } \\
\text { de cada batelada }\end{array}$
\end{tabular}

Fonte: Elaborada pelos autores

\section{Resultados}

$\mathrm{Na}$ fase inicial foram efetuadas 15 bateladas de forma a obter valores ótimos do tempo de eletrólise e do tempo de flotação. Dessa forma, para definir o tempo ótimo de eletrólise foram efetuadas 9 bateladas, a primeira com duração de $10 \mathrm{~min}$, a segunda com duração de $15 \mathrm{~min}$, a terceira com duração de 20 min, a quarta com duração de 25 min, a quinta com duração de $30 \mathrm{~min}$, a sexta com duração de 35 min, a sétima com duração de 40 min, a oitava com duração 45 e a nona com duração 50 min. Baseando-se nos resultados de remoção de DQO e turbidez, o tempo de $45 \mathrm{~min}$ foi escolhido para a operação do sistema nas fases posteriores. As Figuras 2 e 3 apresentam as variações de DQO e turbidez respectivamente.

Figura 2 - Variação de DQO

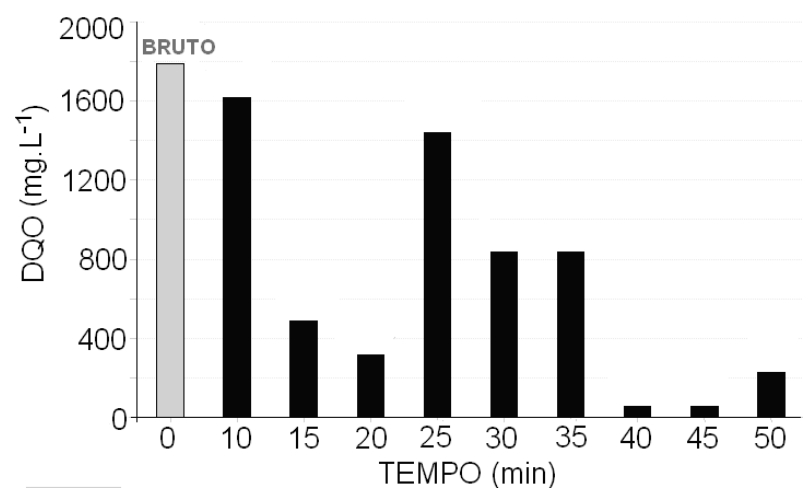

Fonte: Elaborada pelos autores 
Figura 3 - Variação de turbidez

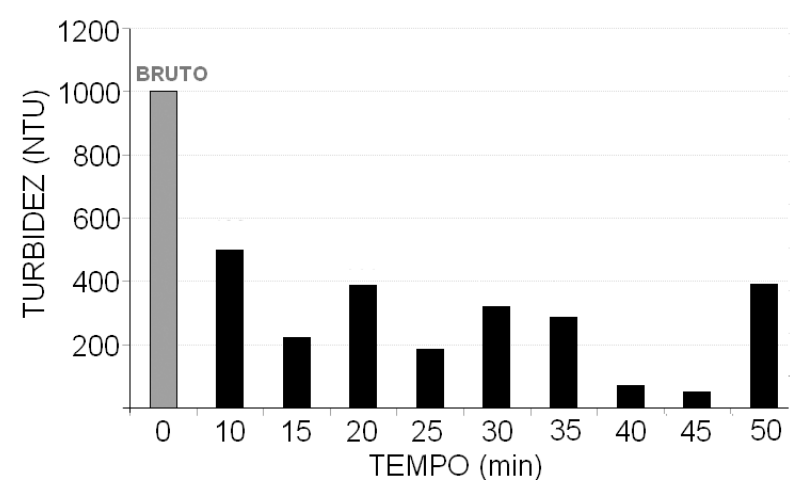

Fonte: Elaborada pelos autores

O pH permaneceu no valor médio de 9,6 para os tempos testados nesta fase da pesquisa.

Uma vez definido o tempo de eletrólise, foi promovia a variação do tempo de flotação as ser aplicado depois dos 45 min de eletrólise. Para isso foram efetuadas 6 bateladas adicionais, aplicando tempos de flotação de 10,20,30,40, 50, e 60 min para as bateladas 10 a 15 respectivamente. Os resultados apresentados nas Figuras 4 e 5 mostraram que o tempo de $20 \mathrm{~min}$ foi o que apresentou melhores resultados

Figura 4 - Variação de DQO

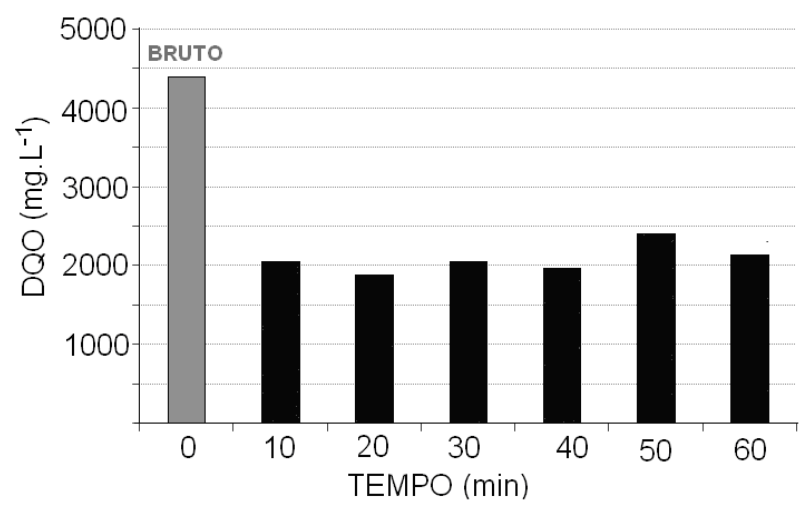

Fonte: Elaborada pelos autores
Figura 5 - Variação de turbidez

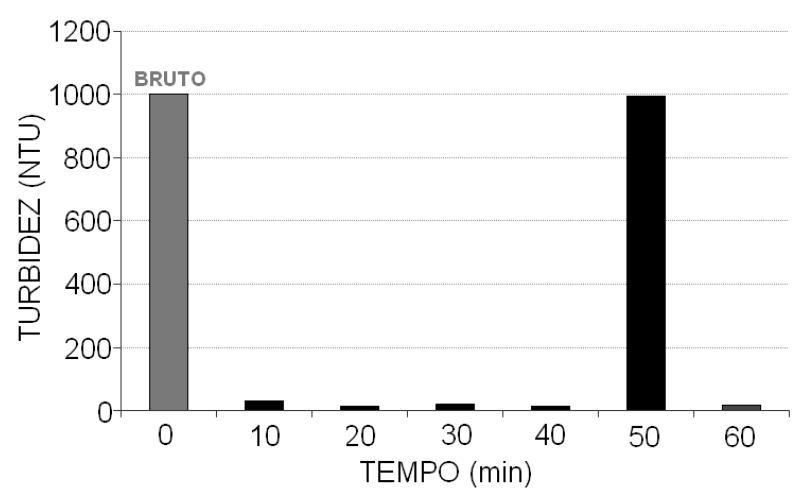

Fonte: Elaborada pelos autores

As Figuras 6 e 7 mostram a variação da concentração de sólidos totais e sólidos voláteis totais ao longo da primeira fase de operação do sistema, ao passo que as Figuras 8 e 9 mostram a variação da concentração de sólidos totais e sólidos voláteis totais ao longo da segunda fase de operação do sistema. As Figuras 10 e 11 mostram a variação de sólidos fixos totais durante a primeira e segunda fases. Nessas figuras, o tempo no eixo das abscissas representa o tempo percorrido depois de efetuar cada batelada, com duração de 45 min de eletrólise mais 20 min de flotação.

Figura 6 - Variação da concentração de sólidos totais na primeira fase de operação do sistema.

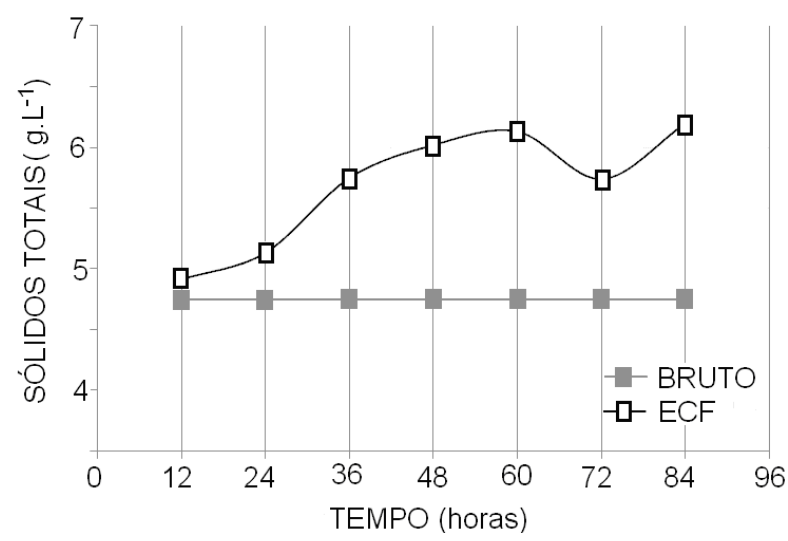

Fonte: Elaborada pelos autores 
Figura 7 - Variação da concentração de sólidos voláteis totais na primeira fase de operação do sistema.

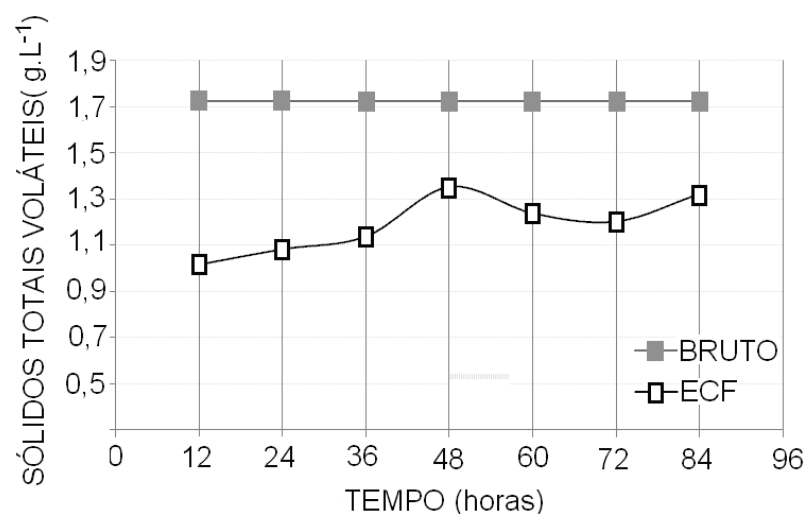

Fonte: Elaborada pelos autores

Nota-se que devido à adição de $\mathrm{NaCl}$ os sólidos totais apresentaram tendência crescente no lugar de serem removidos. A concentração do $\mathrm{NaCl}$ dentro do reator foi em média igual a 1,75 g.L-1, aproximadamente igual à metade da concentração média de sólidos fixos apresentada pelo efluente industrial bruto.

Como se sabe, a concentração de sólidos fixos totais inclui os sólidos fixos suspensos e os sólidos fixos dissolvidos. Somente os sólidos fixos totais e os sólidos voláteis totais foram analisados no presente trabalho.

Os sólidos voláteis, predominantemente em suspensão, mostraram decaimento em decorrência do arraste dos mesmos pelas bolhas geradas na eletrólise.

A análise das Figuras 8 e 9, que mostram o comportamento do sistema quando os valores dos parâmetros monitorados foram determinados antes de cada batelada, permite verificar que a eficiência do sistema é afetada pela variação da qualidade do efluente industrial bruto, mas o acúmulo de sólidos totais e diminuição de sólidos voláteis totais que acontecia na Fase Inicial ainda é observado.
Figura 8 - Variação da concentração de sólidos totais na segunda fase de operação do sistema.

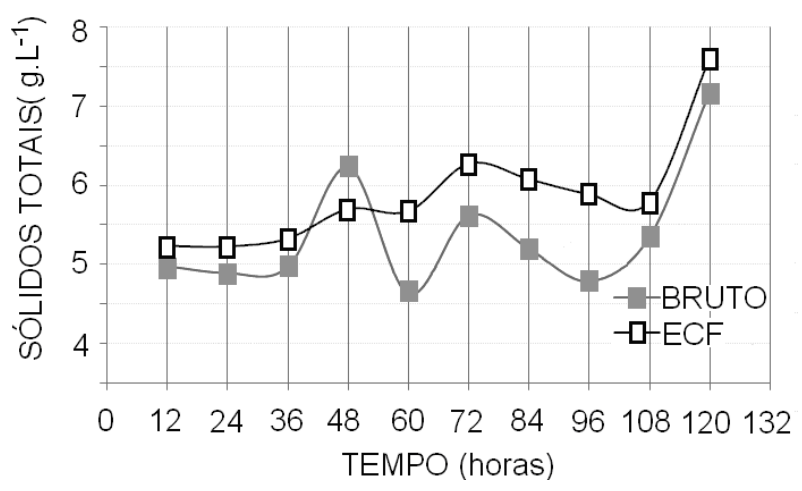

Fonte: Elaborada pelos autores

Figura 9 - Variação da concentração de sólidos voláteis na segunda fase de operação do sistema.

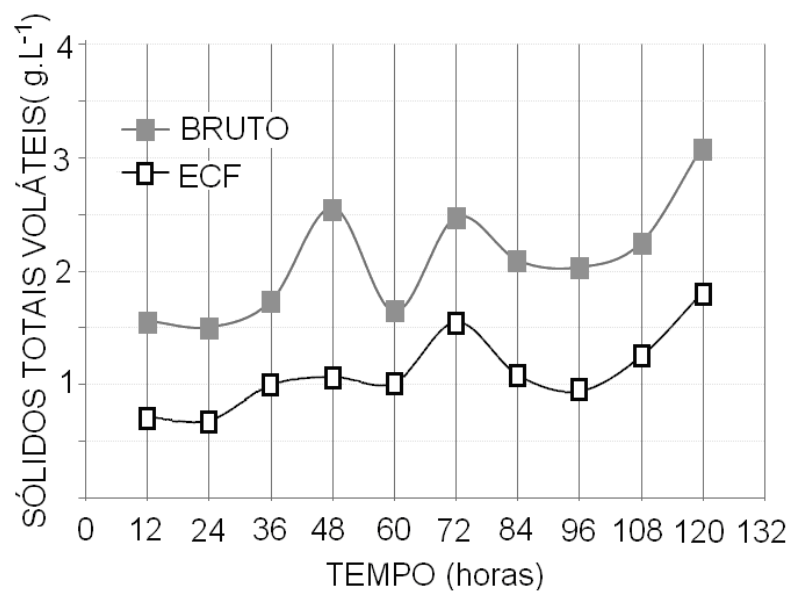

Fonte: Elaborada pelos autores

Nas Figuras 10 e 11 nota-se a presença de sólidos fixos totais decorrentes do sal adicionado e dos sólidos fixos totais presentes no afluente. Em média, pode-se inferir a partir desses dados que o despejo está constituído por igual proporção de sólidos voláteis e fixos. 
Figura 10 - Variação da concentração de sólidos fixos na primeira fase de operação do sistema.

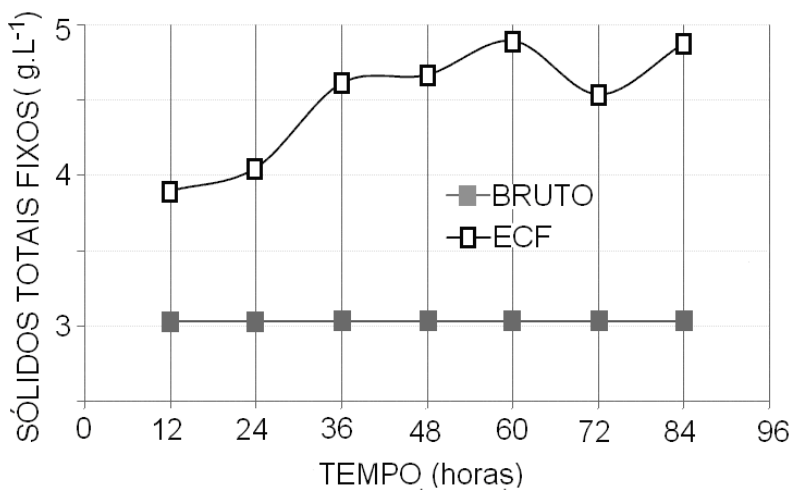

Fonte: Elaborada pelos autores

Figura 11 - Variação da concentração de sólidos fixos na segunda fase de operação do sistema.

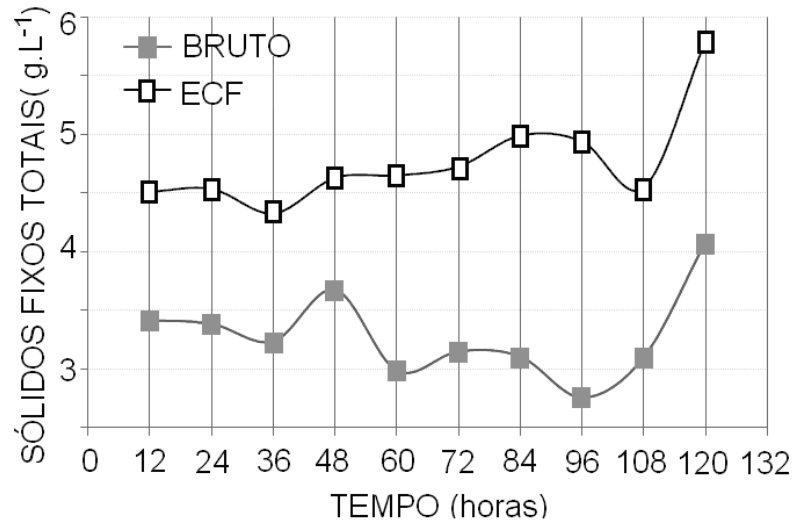

Fonte: Elaborada pelos autores

Finalmente, as Figuras 12 e 13 mostram a remoção de DQO relacionada com o processo. Sendo a remoção de DQO total (DQO particulada + DQO dissolvida) maior que a remoção de SV, pode-se inferir que uma porção do material orgânico dissolvido foi removida por outro processo além da flotação. Esse processo poderia ser a adsorção do material nos flocos formados e a posterior remoção por meio da retirada, desde a superfície do reator, do material flotado. Outra explicação para esse fato seria a eletro-oxidação do cloreto no ânodo para $\mathrm{Cl} 2$ que reage rapidamente com a água para formar $\mathrm{HOCl}$ ou $\mathrm{OCl}$ - que, além de possuírem efeito desinfetante, reagem com a matéria orgânica oxidando-a (HERLEM; TSAI, 2000).
Figura 12 - Variação da concentração de DQO na primeira fase de operação do sistema.

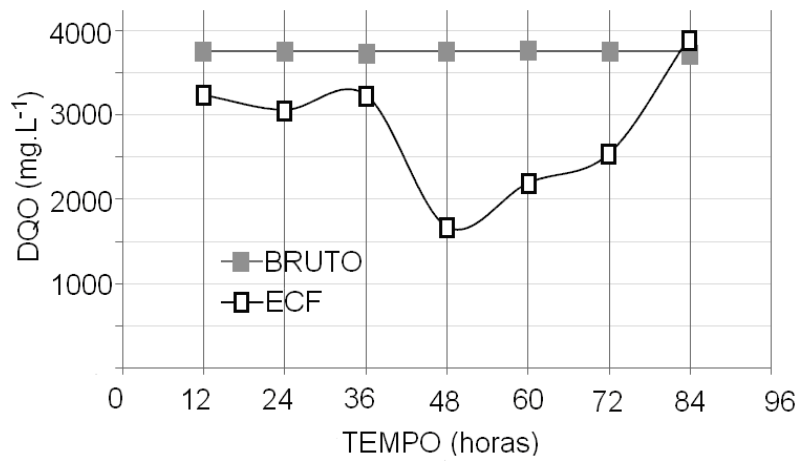

Fonte: Elaborada pelos autores

Figura 13 - Variação da concentração de DQO na segunda fase de operação do sistema.

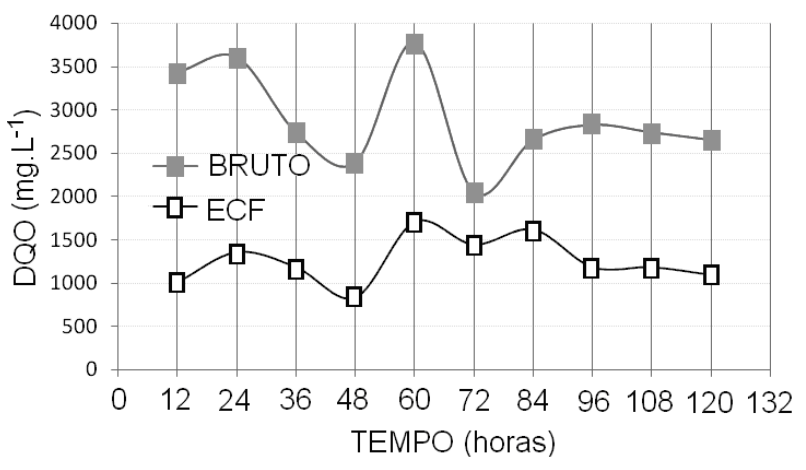

Fonte: Elaborada pelos autores

Nas figuras 6 a 13, pode-se evidenciar o efeito das variações apresentadas pelo efluente industrial bruto. $\mathrm{Na}$ primeira fase, mesmo não tendo caracterizado o afluente antes de cada batelada, pode-se verificar a grande variação na qualidade do efluente tratado. Já na segunda fase, em que o afluente era caracterizado antes de cada uma das bateladas efetuadas, a variação da qualidade salta à vista. É interessante notar que a características do efluente tratado acompanham as variações do afluente bruto, por quanto poderia se inferir que a remoção em porcentagem é aproximadamente constante. 


\section{Conclusões}

A partir dos resultados obtidos podemos verificar que aplicando $45 \mathrm{~min}$ de eletrólise e $20 \mathrm{~min}$ de flotação antes da retirada do efluente final, o reator ECF pode alcançar uma eficiência máxima de remoção de sólidos voláteis de $40 \%$ e eficiência de remoção de DQO de 55\%. Essa diferença é provavelmente decorrente do consumo de DQO por outros mecanismos tais como oxidação por $\mathrm{Cl} 2$ e adsorção nos flocos formados.

Notou-se aumento de sólidos totais e fixos no lugar da remoção dos mesmos, como consequência do $\mathrm{NaCl}$ que foi adicionado visando aumentar a condutividade do despejo.

\section{Agradecimentos}

Os autores desejam agradecer à Fundação de Amparo à Pesquisa do Estado de São Paulo, FAPESP pelo suporte financeiro do trabalho.

\section{Referências}

APHA, AWWA, WEF, Standard methods for the analysis of water and wastewater. 20 Ed. McGraw Hill, 1998.

EMAMJOMEH, M.; SIVAKUMAR, M. Review of pollutants removed by electrocoagulation and electrocoagulation/flotation processes. Journal of Environmental Management, London, v. 90, p. 16631679. 2009.

FENG, J.; SUN, Y.; ZHENG, Z.; ZHANG, J.; LI, S.; TIAN, Y. Treatment of tannery wastewater by electrocoagulation. Journal of Environmental Sciences, London, v. 19, n. 5, p.1409-1415, 2007.

HERNLEM, B. J.; TSAI, L. S. Chlorine generation and disinfection by electroflotation. Journal of Food Science, Chicago, v. 65, n. 5, p. 834-837, 2000.

LEFEBVRE, O.; VASUDEVAN, N.; TORRIJOS, M. Halophilic biological treatment of tannery soak liquor in a sequencing batch reactor. Water Research, New York, v. 39, n. 8, p. 1471-1480, 2005.

MURUGANANTHAN, R.; RAJU, G. B.; PRABHAKAR, S. Removal of sulfide, sulfate and sulfite ions by electro coagulation. Journal of Hazardous Materials, Amsterdam, v. 109, n. 1-3, p. 37-44, 2004.
Recebido em 26 Outubro 2011-Received on October 26, 2011.

Aceito em 5 Dezembro, 2011 - Accepted on December 5, 2011. 
